\title{
Moulding the Museum Medium: Explorations on Embodied and Multisensory Experience in Contemporary Museum Environments
}

\section{Laura De Caro}

\section{(2) OpenEdition \\ 12 Journals \\ Electronic version \\ URL: http://journals.openedition.org/iss/397 \\ DOI: $10.4000 /$ iss.397 \\ ISSN: 2306-4161 \\ Publisher \\ ICOM - International Council of Museums}

Printed version

Date of publication: 1 December 2015

Number of pages: 55-70

ISSN: 2309-1290

\section{Electronic reference}

Laura De Caro, « Moulding the Museum Medium: Explorations on Embodied and Multisensory Experience in Contemporary Museum Environments », ICOFOM Study Series [Online], 43b | 2015, Online since 06 February 2018, connection on 01 May 2019. URL : http://journals.openedition.org/iss/397 ; DOI : $10.4000 /$ iss.397 


\title{
Moulding the Museum Medium: Explorations on Embodied and Multisensory Experience in Contemporary Museum Environments
}

\author{
Laura De Caro
}

\author{
Independent consultant - Brussels, Belgium
}

\begin{abstract}
The body is provided with sensory organs for informing it of those environmental conditions that have a bearing on activities themselves. The acquisition of such information is essential for the successful pursuit of these activities, but the process of acquiring it is itself a source of pleasure. We enjoy discovering the nature of our surroundings, and it is just as well that we do because, in a state of nature, a creature's chances of survival are often dependant on its ability to exploit its environment to its own strategic advantage. We need the knowledge that comes from exploration, but we explore because it is fun. This is the basis of what I have called habitat theory (Appleton, 1978, p.4).
\end{abstract}

In The Poetry of Habitat, British geographer Jay Appleton (1978), contributor to the field of Environmental Psychology, provides today's museum 'communities of practice' (Lave \& Wenger, 1998) with an inspiring point of access into the current debate on the value of the museum experience and on ways to renew the impact and social relevance of the contemporary museum medium.

Appleton's reading of the relationship between Man and the environment highlights the centrality of the natural and built environment in the pursuit of human activities, the pleasure that derives from this encounter and the role of the individual's neural system as a complex whole, composed both of perceptual and cognitive mechanisms, as the ultimate key organisational tool of all exploration and discovery. While this relationship constitutes an important component of scientific discourse, current museum research and practice have yet to reach an understanding of the embodied dimension of the museum visit, historically set aside in favour of Western visualism. Since Aristotle, vision has been repeatedly assigned a prime role in the hierarchy of the senses and in the construction of knowledge. In the museum context, this traditionally corresponded to a fundamental reliance on visual inspection and technologies of visual communication for the interpretation of artefacts and visitor learning (Edwards, 2006).

If visualism in history has perhaps been overstated by contrast to other forms of cultural sensory ratios, a contemporary reframing of vision in the museum as "integral to other sensory modalities" (Edwards, 2006, p. 4) has in recent times become ever more pressing. With museums increasingly encouraged by funders and stakeholders to reflect on their social value and the success of their communicative tools, the limits of visual engagement have become rapidly manifest, suggesting the value of research in holistic visitor experience, as composed by a set of personal, social and physical factors (Falk \& Dierking, 1992). Following Appleton (1978), the visitor's pursuit of pleasure and satisfaction deriving from the exploration of different physical components in the museum 
(architecture, space, display, objects) thus warrants studies on its full multi-sensory dimension, shedding light on the potential impact of physical and environmental factors in learning and meaning-making processes.

Approaching the museum experience from an 'embodied' rather than cognitive or social perspectives allows the visitor to assume an active role: no longer a passive recipient of content, the visitor is recognized, in line with contemporary threads of museum theory, as an actor in a dialogic multisensory process of communication with his/her surroundings, in which he/she is fully immersed. The 'gaze' towards the object in the museum 'treasure house' (Witcomb, 2003) becomes one aspect of an enveloping bodily experience within a complex environment. The museum no longer acts primarily as a place for the gathering and communication of knowledge, but for the gathering of different forms of experience (Falk \& Dierking, 1992). This perspective supports a constructivist approach to museum use and learning and reinforces a more flexible, cultural model of communication that replaces the traditional transmission model of mass media theory.

Shifting attention from the knowledge of the collection to the user of the museum, an understanding of the embodied dimension further allows us to focus on one defining, often forgotten characteristic specific to the museum medium: its spatial dimension. Usually regarded as an index for the rich collections it beholds, the museum has been considered throughout history as an object-based medium, implying that its communicative power be somewhat reduced to the communicative process between visitor and object. Today, the rocketing development of multimedia display techniques and debates over museums without objects have questioned this association (Conn, 2010), so that, without losing their primacy as the key distinctive richness of the museum institution, objects have become part of a complex interconnected set of media. Architecture, display interactives and environments today work in unison with objects and text to support not only thematic content but also opportunities for visitor meaning-making and participation (Skolnick, 2005). In virtue of its mediating capacity to tell stories and generate engagement, the museum can thus be read as an inhabitable three-dimensional narrative space ${ }^{20}$, part of the ecology of urban and social life, where meanings and identities are constantly constructed, contested and reinforced.

The ecological metaphor adopted so far also suits our purposes for a third reason: it implies a system of constant interdependency among the 'populations' that inhabit museum space and participate in its daily practice. In contemporary museums, external stakeholders, working staff, professional consultants and audiences all contribute to the messages and social relevance of the institution. Balances of power and dialoguing forces not only have an impact on content organisation and storytelling, according to historical and social contingencies, for example in the representation of conflict, colonisation and minorities, but actively define the success of museum activities. Architects, curators and managers, to name only a few, contribute to the design of museum experience with their own interpretations of museum purposes and communicative models. Such interpretations may work in line or in collision with the views of

\footnotetext{
${ }^{20}$ The subject of narrative space was addressed at the conference by the same name at the University of Leicester, $19^{\text {th }}-22^{\text {nd }}$ of April 2010.
} 
the museum's multifaceted audiences, and while visitor studies have forcefully attempted to address this gap, the success and power of involvement of exhibitions and museum-going are still very much determined by factors associated with professional collaboration.

In recent years, significant transformations have swept across the museum sector multiplying visitor numbers through marketing-led communication, large capital investments, blockbuster exhibitions and social networking and, even in times of financial restraint, this process is ongoing. If such transformations have intensified debate over the changing role of the museum in the social landscape, then this is probably a particularly fitting time for museum practitioners to go back to the basics of the museum-visitor relation, addressing questions on the specificity of this medium in the wider context of culture-related media and production (Henning, 2006).

In this quick-paced social and economic context, visitor studies in the UK have largely explored visitor segmentation, motivation and interests. The present paper hopes to encourage a widening of scope for research, exploring the embodied sensory experience and suggesting initial answers to the questions: How do museum space and the senses collaborate and contribute to visitor experience? Can the embodied dimension have a role in narrative processes and learning as well as enjoyment? To what extent is there awareness among museum practitioners of the spatial and sensory potential of the museum environment? Setting temporarily aside sensory approaches based on single hands-on exhibition displays, a wider enquiry on the visitor journey, the involvement of the senses and the role of architecture, space and display would encourage a fresh look on the museum medium. In support of its role as a learning environment, it would also help imagine a more flexible set of social functions for its future.

While this study focuses on the embodied visitor experience, its purpose is, finally, to test the malleability of the medium in conversation with museum practitioners. In 1969, Marshall McLuhan, one of the fathers of media studies, identified this very special trait of the museum in a seminar entitled "Exploration of the ways, means and values of museum communication with the viewing public" at the Museum of the City of New York. Together with designer Harley Parker, he spoke to an audience of museum directors about the 'modular' quality of museums (Deloche \& Mairesse, 2008). The museum was presented as a flexible medium

of which we can change the rules; and that is, by its very nature, a means of access to the sensory and intuitive perception of all things (Deloche \& Mairesse, 2008, p. 15).

The title "Moulding the museum" is thus a reminder of the immense heritage and histories that offer the mould out of which today's museum institutions are cast, but which can, nevertheless, give shape to something contemporary and not reducible to a superficial make-over of architecture and display, but to a potential revision of values. Visitor, object, medium and professional boundaries each find their place in a revised contemporary museum ecology. 


\section{Communication, learning theory and the sensory museum environment}

The parallel shift from positivistic transmission models in communication and learning theory to models that "acknowledge people as active in making sense of social environments" as HooperGreenhill (1994, p. 71) notes, is part of a wider postmodern stance, which sees reality as plural and relative, as a social construct subject to change.

For museums, this means conceptualizing visitors as participative in meaning-making, as actors in the communicative and learning processes encouraged by the museum. In terms of embodied experience, the figure of the visitor is thus read as one that enables museum space, architecture and objects to communicate, to be inhabited, to assume value. The visitor acts as the vector that allows meaning to develop through movement, linking elements according to personal, social and physical factors. While the museum is the facilitator of communication, in other words the medium, the visitor is the activating element of the communicative process, through a process of selection, reception, regeneration of ideas.

Furthermore, a communicative reading of the museum should not be limited to exhibitions, for not only objects or audio-visual media but all the sensory stimuli of the museum visit, from the welcoming staff and orientation to the building, bookshop and displays, become part of the holistic communicative experience of the visit (Hooper-Greenhill, 1994). This view appears valuable not simply in branding and marketing terms, but in order to understand the interconnectedness of different elements as part of one communicative experience. In this perspective, the embodied dimension of the visit plays a role in all museum typologies, allowing the visitor to select and compose elements that will build a personally constructed experience of the museum visit.

As Michelle Henning (2006) notes, one limit of communication theories applied to museums is the tendency to focus on information and not account for the experiential and affective appeal of museums and exhibitions. In such theories, material objects are treated as "concrete instances of an abstract schema" (Henning, 2006, p. 71) while exhibits experienced in bodily terms, through the activities and sensations they engage, could constitute a significant part of the museum experience alongside more explicit messages. It is notably the material aspect of museums that seems to distinguish them from other media, as the latter "detach objects, scenes, people from a fixed place in time and space and allow them to circulate as multiples" (Henning, 2006, p. 71).

Traditional museums certainly prioritized "objects, permanence and [the] unique" and in such contexts, media may have seemed to threaten the aura of original objects. However, today museums are becoming increasingly mediatic, bringing objects closer to the visitor through reconstructions and new media, certainly sharing with other media a distinct recording and storage function, to bring the past into the present and preserve the traces of culture. As Henning (2006) reminds us, the history of the modern museum corresponds chronologically with the history of recording media.

But what is characteristic of the museum medium in terms of visitor experience? Eilean Hooper-Greenhill (1994) highlighted the immense 
advantage of museums to enable mass media communication as well as 'natural' face-to-face dialogue with guides, staff and amongst visitors. Stephen Weil (2002) extends this view further, reminding us of the "relative informality" of the museum environment, where rules of conduct have been tempered to make the visitor experience more enjoyable. This is something museums seem to share with television, which, having become part of our daily life, elicits dialogue, listening, questioning, zapping - in other words engagement and selection - as a medium part of our 'habitat' that we need not leave, one could say, when the programme is over. In his 1967 seminar, Marshall McLuhan explained this clearly: while the traditional museum is a derivate of print, exclusively linear and visual, detached from the environment and precluding any chance for sensory engagement, the museum of the future has the potential to become a 'cold' medium - similar to television - multisensory and requiring the active participation of the subject. The 'linear' museum would thus give way to the "exercise of perception, that's what the museum world could focus on" (McLuhan, 2008, p. 40) to allow the functioning of all the senses, the full range of human explorative tools. For McLuhan, thus, space does not coincide with visual space:

\begin{abstract}
the true artefacts produced by Man create environments and not simply objects within such environments. For different reasons, biological or physiological, people don't perceive environments but only the content of such environments (Deloche \& Mairesse, 2008, p. 48).
\end{abstract}

In this line of thought, the museum becomes a context for social practice, a living and sensory environment where, in virtue of its collections, media and spatial dimension, a range of sensory experiences can be lived in a variety of participative ways.

As stated by John Falk and Lynn Dierking in The Museum Experience, in learning theory the role of physical engagement analogously often has been forgotten,

\begin{abstract}
People learn within settings that are at once physical and psychological constructs. The light, the ambience, the "feel" and even the smell of an environment influence learning (...) Experiences that are the hardest to verbalize can be the easiest to recall. For this reason, the role of the physical context upon learning has been one of the most neglected aspects of learning (Falk \& Dierking, 1992, p. 100).
\end{abstract}

In their Contextual Model of Learning, learning is understood as an active process of assimilation of information with an equal degree of attention for the influence of personal, social and physical contexts. Learning is read by these authors as a 'free-choice' process, in which the learner has choice over what, why, where, when and how he/she will learn. It can happen in any context, formal or informal, and it happens continuously. Falk and Dierking's (1992) intent is to present a fuller picture of the visitor's total museum experience, recognizing variables of motivation, beliefs, attitudes inherent to the personal context as well as influences of the social and physical contexts whether conscious or not, "Each of these contexts is continuously constructed by the visitor and the interaction creates the visitor experience". According to these authors, where one is has an enormous impact on how, what and how much one learns, and this should push museum practitioners to focus efforts on the creation of an environment, in which the visitor "becomes part of a seamless array of mutually reinforcing contexts" (Falk \& Dierking, 1992, p. 130). 
Such a perspective, endorsed by Environmental Psychology, reconnects with Mihaly Csikszentmihalyi's (1996) flow theory, whereby embodied engagement and its explorative nature can contribute to provide the visitor with a sense of being freed from worries, of feeling competent and in control, of finding tasks appropriate to personal abilities and obtaining feedback from the environment (Falk \& Dierking, 2002). In other words, by working on physical aspects and embodied experience, the museum can generate an environment for learning and creativity, allowing visitors to retain more, enjoy more and make the visit relevant to their skills and knowledge.

Attending to embodied and experiential factors also responds to models of learning such as David Kolb's (1984) experiential learning theory and learning styles and Howard Gardner's (2011) theory of multiple intelligences. In Kolb's theory, learning is grounded in concrete experience, the first step of a cyclical process that allows reflections and observations to be distilled into abstract concepts and reapplied in concrete contexts. He also identifies different learning styles, distinguished within a spectrum of forms of engagement with the outside world, underlining the variety of personal approaches to interpretation and a varying balance between watching and doing, thinking and feeling, in the process of grasping and transforming experience. Gardner's (2011) theory, in line with such thinking, identifies seven forms of intelligence, among which the visual-spatial, bodily-kinaesthetic and musical present particularly distinct sensory and spatially-defined qualities. As Falk and Dierking accurately summarize, "Learning and memory are subjective and contextually influenced" (1992, p. 112).

Such perspectives are also strongly echoed by the recent development of a constructivist approach to museum practice. As expressed by George Hein (1998) in The educational role of the museum, constructivism recognizes that both knowledge and the way it is obtained depend on learners. Hein invites practitioners to reflect: What is done to acknowledge that knowledge is constructed in the mind of the learner? How is learning made active and how is the environment designed to make it accessible? He encourages a perspective coherent with Howard Gardner's and David Kolb's learning theories and strongly recognizes the role of place, architecture and atmosphere on learning processes, declaring that museum spaces are often "designed with little concern for the needs of visitors for privacy and comfort in order to learn"(Hein, 1998). In his view, the constructivist museum should include at least some spaces as "settings for relaxed, engaged activity which can take time and in which visitors would feel safe" (Hein, 1998).

In this theoretical frame, studies in environmental psychology, such as those assembled in two meaningful collections of essays - Falk and Dierking's (1995) Public Institutions for Personal Learning and the interdisciplinary journal 'Environment and Behavior' (1993) constitute an important knowledge base to grasp connections between learning and environment. In the first publication, Alan Hedge (1995) explores the 'human factors' of the museum visit, with reference to Csikszentmihalyi's theory of intrinsic motivation, understanding 'flow' as a confluence of mental and physical processes that produce optimal experiences. He suggests that settings should be designed to provide the basic requirements of flow: purpose, attention, challenge, involvement, feedback, immersion, 
control and sense of time. In the second publication, Marilyn G. Hood (1993) analyses 'psychographic' characteristics - attitudes, values and concept of self - exploring how these relate to environmental elements, which she defines the 'comfort and caring' factors of museums. However, particularly important is Gary Evans's (1995) 'Learning and the Physical Environment'. An environmental and developmental psychologist, Evans identifies six links between physical settings and psychological processes: cognitive fatigue, distraction, motivation, emotional affect, anxiety and communication. Contributing to the study of visitor holistic experience and making reference to Stephen Kaplan's (1993) equally significant study on the museum as a restorative environment, Evans reframes the museum not only as an intellectual, social, emotional setting but as a physical entity functional to the stimulation of reflection and learning processes.

In full recognition of these studies, which invite practitioners to locate physical engagement not simply at the lower levels of Maslow's (1970) pyramid of basic needs, but at its different steps in the pursuit of satisfaction, Hein's constructivist theory places the visitor and museum environment at the core of an interactive learning system. In other words, the museum places itself between past and present, between knowledge developed and knowledge to be created, and the point of junction is the multisensory, sensing being of the visitor.

\title{
Theoretical foundations of the embodied experience in space
}

\begin{abstract}
All architecture functions as a potential stimulus for movement, real or imagined. A building is an incitement to action, a stage for movement and interaction. It is one partner in a dialogue with the body (Bloomer \& Moore, 1977, p. 9).
\end{abstract}

Spread among different disciplines, studies on embodied experience may appear varied and fragmented; nevertheless they share one common desire: to relocate materiality and sensory experience at the centre of meaning-making and in our engagement with objects, narrative and socio-cultural settings. Without excluding vision, nor diminishing its importance, such studies explore how the individual, who 'knows' and 'lives' through the whole sensory register, is in contact and dialogue with the external world and, in the case of museums, how narrative and experience are vehicled, in the first instance, through such multisensory understanding.

In one important collection of writings on the subject of embodied relations with objects, Museum Materialities. Objects, engagements, interpretations, Sandra Dudley (2010) explains how the 'material' turn of many disciplines in the last twenty years, typically that of material culture studies, has brought an understanding of material objects as part of social life, for their acquired meanings and values, paradoxically leading attention away from,

\footnotetext{
the tangibility of material surfaces, encouraging us instead to leap straight into analysing the role of objects in social and cultural worlds, in the process missing out an examination of the physical actuality of objects and the sensory modalities through which we experience them (Dudley, 2010, p. 2).
} 
According to Dudley (2010), despite a renewed focus on the 'material', questions regarding the way that objects carry meaning and feeling and the specificity of the museum as a place for personobject engagement still remain to be addressed thoroughly.

Within museum-related literature, sensory engagement has been more thoroughly explored in connection with indigenous cultures and colonial pasts, as in the collection Sensible Objects. Colonialism, Museums and Material Culture (Edwards, 2006), as well as with object-handling displays, initially developed in science museums and centres (Caulton, 1998). While the former tackles cross-cultural interpretation and the clash between different sensory systems engendered by colonial encounter, the latter brings forth analyses on the potential of touch as a form of access to interpretation, feeling and reminiscence. Similarly to the more established understanding of multiple intelligences and learning styles, multisensory exploration becomes here a sensitive, democratic tool, to address the needs and interpretive discourses of different museum populations. No longer considered a necessity uniquely for the visually impaired, multisensory exploration is reconnected to the very purpose of the museum: providing readings of objects and stories respectful of different cultural sensory ratios. In these terms, physical and sensory engagement is understood in terms of spatial politics, community ownership and social agency (Golding, 2009). To this purpose, an expanding literature in the history and anthropology of the senses, notably the writings of David Howes (2004) and Constance Classen (1994), provide a fundamental repository of interpretive readings revealing the diversity of assigned meanings in history and across cultures.

The topic of embodied experience has also successfully concerned museum education departments, looking to channel visitor experience across a range of multisensory possibilities. In her article published in Art Education, Olga Hubard (2007) explains that, as cognitive science confirms the rootedness of concept and reason in the experience of the body, a reconsideration of the status of the body in the construction of knowledge offers important opportunities in art education,

There is a sense of immediacy in the way the viewers begin to apprehend an artwork: a physical, sensorial, and often emotional engagement that precedes the conceptual (Hubard, 2007, p. 47).

Her writings bring out an important key to embodied experience: that perceiving in bodily terms does not forcibly imply physical contact, but rather an understanding through physical means, for example identifying aspects such as texture and size, or using sensory experience to imagine fictional or past environments. Today this kind of approach is developing to extend the possibilities offered by handson exhibits.

It is clear, however, that research has primarily focused on the interaction with artworks and objects, with scarce attention for museum space and overall bodily engagement in the museum. Embodied experience of space and architecture has suffered a scarcity of literature, within and outside the museum world, possibly and partly due to hard-to-define notions of 'bodily engagement' and 'sensory spatial experience'. Kent Bloomer and Charles Moore explain, 
It is not surprising that forms are more often the focus of our attention than space or movement in space. Space is typically thought of as a void or as the absence of solid, and movement thought of as a domain separate from its existence in space (Bloomer \& Moore, 1977, pp. 57-58).

In 1977, they published the results of their research in Body, Memory and Architecture, addressing an important gap in architecture education: the understanding of how buildings are experienced, rather than how they should be built. They observed that reference is "seldom made to the unique perceptual and emotional capacities of the human being" (Bloomer \& Moore, 1977, p. 9) and that even historians mainly focus on the cultural influences of building styles and landscape. Architecture, they affirm, is commonly read as a specialised system, sustained by a defined set of tools and goals, rather than as a discipline responsive to human desires and needs. The human body, "our most fundamental three-dimensional possession, has not itself been a central concern in the understanding of architectural form" (Bloomer \& Moore, 1977, p. 9).

Written in a time when architectural and environmental psychology were gaining ground in response to the relentless building of the previous decade, Bloomer and Moore's words appear starkly contemporary in our time of capital funding for iconic architecture and computer-based design methods. As they explain, in its beginnings all architecture derived from a "body-centred sense of space and place". Things changed with the dawn of industrialisation (Bloomer \& Moore, 1977). This turn also came with a growing predominance of the visual sense. Other means of sensing objects became secondary in the articulation of knowledge and, by the $19^{\text {th }}$ century, three-dimensional forms were treated by architects as visual problems. As Robert Sommers states in Personal Space,

\begin{abstract}
It is curious that most of the concern with functionalism has been focused upon form rather than function. (...) Relatively little emphasis is placed on the activities taking place inside the structure. This is predictable in the case of the architect who, in his training and practice, learns to look at buildings without people in them. (...) Once the structure is opened for public use, the architect disappears from the scene (Sommers, 1969, p. 3).
\end{abstract}

If recent decades have brought evolutions in the architectural profession, Richard Toon (2005, p.26) reminds us that contemporary texts dedicated to museums mostly present images of façades and architectural details. It is also true that the immersive possibilities offered by digital technology and the vast diversity of museum architectural forms created in recent years have provided renewed opportunities to place the visitor at the core of architectural planning. One might argue that it is, in fact, very much thanks to these transformations that spatial, embodied engagement is slowly gaining attention and significance. Some architects, like Tadao Ando for example, place special attention on the lived experience of architectural space. In an interview he states,

The challenge is to conceive a space sufficiently generous to allow each individual to become the centre (...) to put people sufficiently at ease to allow them to explore and find their own way inside the building (Auping, 2007, p. 55). 
Analogously, Peter Zumthor affirms,

\begin{abstract}
I'm interested in spaces (...) that make me slow down a little, that make me stop, take a chair and start reading (...) spaces that invite me to blend into them. Like everyone, I know immediately when I'm 'called' by a space, but I find it difficult to define the precise qualities that provoke that sensation (...) There are spaces that (...) give us a sense of freedom, of dignity (Mostafavi \& Zumthor, 1996, p. 65).
\end{abstract}

As Juhani Pallasmaa explains, we tend to neglect the fact that we exist through our senses and cognitive processes, that we confront spaces and buildings with all our senses, in their multisensory, lived essence,

qualities of space, matter, scale are measured equally by the eye, ear, nose, skin, tongue, skeleton and muscle. Architecture strengthens (...) one's sense of being in the world, and this is essentially a strengthened experience of self (Pallasmaa, 2005, p. 41).

For the museum field, this perspective may suggest a reading of objects, displays and architecture as a continuous flux of sensory stimuli: through the senses we seek out, give shape, select our experience, within an environment inscribed by the assignment of meaning, social hierarchies and personal preferences.

Exhibition design manuals are not unfamiliar with this point of view. Here, "the human being is a design factor that influences and relates to all other composition-related considerations." (Dean, 1994, p. 39). In the history of exhibition design, reflections on the impact of space have brought remarkable transformations, from the innovative exhibition designs of El Lissitzky and the avant-garde in the 1920s to the 'white cube' of the 1960s (O'Doherty, 1999), which has recently witnessed the birth of its negative, the immersive black box (Toon, 2005, p.26). Today design manuals are moving towards performative spaces and simulated experiences, blurring boundaries between market-led display and museum exhibitions (Dernie, 2007). There is now a large recognition among designers of the museum as a spatial medium, although sometimes implying that "the new medium of brand experience is now people" (Dernie, 2007, p. 10) and that "sensory marketing' is only one fashionable aspect of a wider experience economy (Howes, 2004).

Finally, in the recently published Museum Making, Jonathan Hale (2012) offers an important point of junction between theories of embodiment in space and the museum sector. Citing Merleau-Ponty's idea that knowledge derives from the interaction between the body and the space around it, Hale raises a fundamental question on what the museum, as a three-dimensional spatial medium, can offer storytelling and narrative, "within a spatial and, therefore, bodily framework" (Hale, 2012, p. 199) in ways that text alone cannot provide. In the future, a sound experiential and ethnographic enquiry on these notions will hopefully come to enrich current trends, in support of museum architecture and the design of creative spaces (Skolnick, 2005) which, very much like theatre, are increasingly eliciting public performance, inhabitation, in a metaphorical 'open circle' with diversified audiences. 


\section{The case-study}

Rare are the exhibition projects that, even today, take full advantage of this growing body of literature. The tight programme schedules of most museum institutions, the budget cuts for development and investment, the long-term calendar of travelling exhibitions may all, undoubtedly, play their role. However, to conclude this incursion on the subject of embodied and bodily forms of engagement, one exhibition, chosen among the case studies of a more extensive piece of research, was chosen here to show one of the varied ways in which curatorial and design teams can invite visitors to find their place within spatial narrative. It constitutes a case solidly grounded in embodied and multisensory visitor experience, a model of best practice, both in the use of media-intensive environments and soundbased forms of storytelling.

Fare gli Italiani (The Making of Italians), was a year-long exhibition part of the nation-wide celebrations of the $150^{\text {th }}$ Anniversary of Italian Unification in 2011. As one of the three most-visited exhibitions in Italy for nine consecutive months, reaching a total of 362,000 visits ${ }^{21}$, Fare gli Italiani was hosted in Turin, in one of the naves of the Officine Grandi Riparazioni (OGR) ${ }^{22}$, a $200 \mathrm{~m}$-long open space characterised by cast-iron columns and rail tracks, left mostly in their original state. As Design Director Paolo Rosa explained, the task was a challenging one. In tight collaboration with Walter Barberis and Giovanni De Luna, historians and curators responsible for the project, the team worked around the core questions: 'How have these 150 years of national history brought Italians together? Have they been successful in achieving the process of Unification?' (W. Barberis, personal communication, November 21, 2011).

Space and content, Barberis explains, influenced each other from the outset, for this piece of 'industrial archeology' suggested special kinds of solutions, different from those of a traditional exhibition of objects. The exhibition was defined to have a media-rich articulation, which called for the participation of Studio Azzurro, one of Italy's most renowned art collectives and design teams, founded by Paolo Rosa and his partners in 1982 with a mission to explore polysensory environments and connections between physical space and the electronic image. Studio Azzurro's early experimentation in video environments, theatre and performance sharply impacted their recent collaborations with the museum world. Maintaining focus on the interaction between the individual and the virtual space of video projections, this encounter led to the more recent development of narrative habitats: a special form of sensitive environment that reacts to the presence of the individual in seemingly natural ways, without the use of hands-on interactives, thus blending technology, narrative and space in an embodied, immersive whole (Cirifino, 2011).

The $10,000 \mathrm{~m}^{2}$ exhibition space of Fare gli Italiani was transformed in a journey across "the morphology of Italy": against a dark backdrop, visitors are confronted with a theatrical landscape of bright thematic islands, connected by chronological self-lit panels, or "currents". Making use of heights and offering viewing platforms, or "belvedere" (Rosa, 2011) across the exhibition space, visitor are presented with the thematic variety of the Italian territory, an open, visible scenario made possible by the OGR space, where one can move around

\footnotetext{
${ }^{21}$ Data kindly provided by the OGR Marketing Office.

${ }^{22}$ These were once the railway workshops of the city of Turin.
} 
freely, encountering "unexpected corners (...) reverberations (...) objects" (Rosa, 2011, p. 7).

The narrative structure, organised in fourteen thematic stations (Church, Migration, Industry, Mafia, etc.) and exploring social cohesion and separation, uses two main communicative channels: an immersive media-rich environment, triggering emotional involvement through physical and multisensory interaction as a point of access to the theme; and secondly, a series of "balustrades", low self-lit glass cases with collections of texts, photos, objects, videos and audio constituting the documental base for each theme, with a distinct internal chronology.

Between stations, chronological panels enlarge the interpretive lens on the social events discussed, offering timelines, pie charts and didactic material for visiting schools. As Rosa explains, it is not despite but thanks to emotional forms of engagement that in-depth information is sought out, "We come into a world and firstly, we breathe in that world, secondly we want to understand it. The two dimensions are not in contrast" (P. Rosa, personal communication, November 21, 2011).

\section{Planning for participation and embodied experience}

Common to the individuals involved in the project was the recognition that choosing a space such as OGR implied a different communicative intent, placing industry within a reflection on identitymaking processes, and that this demanded an exhibition project centred on social participation rather than object-based narrative,

For us, the object was relevant only insofar as it was
indicative of and informative on the presence of Italians
(...) something closer to elements of scenographic
narration than to a symbolic dimension. (..) Garibaldi's
sword...no, not at all! $(\ldots)$ But it was also not our intention
to have a continuous interference by multimedia systems.
This was the great contribution of Studio Azzurro (...) The
only real fundamental object of the exhibition is in fact the
building (W. Barberis, personal communication,
November 21,2011$)$.

The recurring image of the exhibition thus becomes social "plurality" (Rosa, 2011), a narrative "polyphony" of personal stories and memories that connect historical facts to the complexity of the Italian territory and the experience of single individuals. Within this operative context, embodied visitor experience enabled thus a form of participation in direct and vivid response to the narrative objectives of the exhibition. The use of sound and touch are recognized by the curators, designers and educators as having cognitive value for multiple audiences, potentially "functional to a certain storytelling and communicative objective, and not simply as an impressive tool" (P. Rosa, personal communication, November 21, 2011).

For Design Director Paolo Rosa, the use of immersive media environments is not born from a "research of spectacle" but from the intent of activating a poetic, evocative dimension that may touch a highly diverse public, placing the body, the senses and memory in direct connection with content. Firstly, the body of the visitor is placed, as in the section on Cities, on a 1:1 ratio with the figures projected on the screens, facilitating specular relations between real and 
imaginative contexts. Secondly, the unitary experience of the previous generations is enacted in bodily terms, through moments of aggregation, listening, movement and lifting objects. For example, in 'Cinema', the reconstruction of an open-air cinema allows visitors to aggregate and comment the classics of Italian film; in 'School', by rubbing a sensitive blackboard, the visitor reveals changing class pictures of different generations; in 'Migrations', a large net full of luggage hanging from the ceiling releases video projections of fallen suitcases that, cued by the movement of the visitor, tell stories of immigration connected to the projected objects.

Each time, a full-size object is used as representative icon of the theme (the parachutes of war or the earth pit of Mafia killings) around which narration unravels. Visitors are invited to sit on the sand bags of World War I barricades and listen to voices reading letters to the front, or, take a chair in the Political Participation section and listen to the political propaganda that preceded the Italian Constitution. In the Mafia section, confronted with an endless library of trial case folders, one can pick up folders and place them on sensitive platforms, activating large screens with pictures and data on victims and perpetrators. As Rosa explains, the intent is to create "antibodies" to the isolating effects of technology and find uses for media within "relational spaces", where design and curatorial interventions are responded to with positive acts, experimenting time frames and ways of being in physical and social spaces ( $P$. Rosa, personal communication, November 21, 2011).

These bodily operations not only place media, as Rosa adds, at the core of our cultural heritage but assign touch and sound a privileged place in visitor identity-making processes, through stimulus-generated responses: tuning in to the radio news of war, taking old photographs, finding one's personal memories among advertised objects and old television anchormen. A rich variety of personal stories and witness accounts also play a role in the form of political speeches, song, recollections of students, combatants and blue-collar workers, voices of emigrants and of radio and television programmes. "Remembrance is an ingredient of history," explains Barberis, "that needs to be treated (...) sorted, because remembrance is an experience that cannot always be generalised" (W. Barberis, personal communication, November 21, 2011). Sound, touch, smell can each provide distinct forms of involvement, favouring tighter relations, for example, with the ephemeral and immaterial. They may bring an important "poetic" dimension to the narrative habitat, making the museum more eligible to becoming, in the future, a social, cultural and physical "space for ritual",

$$
\begin{aligned}
& \text { we could not remain indifferent ... the empty silent spaces } \\
& \text { of OGR immediately spoke to us of incessant work, of } \\
& \text { frantic movement, of metallic sounds and the bright glow of } \\
& \text { the blowtorches (...) of how enchanted stillness (..) can } \\
& \text { reveal the vitality of its past ( } P \text {. Rosa, personal } \\
& \text { communication, November } 21,2011) \text {. }
\end{aligned}
$$

By coming into closer contact with the basics of the visitor-museum relation and recognizing its ecological or "territorial" function of place-, habitat-, identity-making, the museum can maybe find its place more firmly among other mass media, not only for its direct links with recording, reconstruction and discovery, but in virtue of its 'emplaced' social experience. 


\section{References}

Appleton, J. (1978). The Poetry of Habitat. Hull, UK: Landscape Research Group and Dept. of Geography.

Auping, M. (2007). Du béton et d'autres secrets de l'architecture. Sept entretiens de Michael Auping avec Tadao Ando lors de la construction du Musée d'Art Moderne de Fort Worth. Paris : L'Arche.

Bloomer, K. C., \& Moore, C. W. (1977). Body, Memory, and Architecture. New Haven, USA: Yale University Press.

Caulton, T. (1998). Hands-on exhibitions. Managing interactive museums and science centres. London, UK: Routledge.

Cirifino, F. (2011). Studio Azzurro. Musei di Narrazione. Percorsi interattivi e affreschi multimediali. Milan: SilvanaEditoriale.

Classen, C. (Ed.). (1994). Aroma. The Cultural History of Smell. London, UK: Routledge.

Conn, S. (2010). Do Museums still need Objects? Philadelphia, USA: University of Pennsylvania Press.

Csikszentmihalyi, M. (1996). Creativity. Flow and the psychology of discovery and invention. New York, USA: HarperCollins.

Dean, D. (1994). Museum Exhibition: Theory and practice. London, UK: Routledge.

Dernie, D. (2007). Exhibition Design. London, UK: Lawrence King Publishing.

Deloche, B., \& Mairesse, F. (Eds.) (2008). Le musée non linéaire. Exploration des méthodes, moyens et valeurs de la communication avec le public par le musée. Lyon, FR: Aléas.

Dudley, S. H. (Ed.). (2010). Museum Materialities. Objects, engagements, interpretations. Abingdon, UK: Routledge.

Edwards, E. (Ed). (2006). Sensible objects. Colonialism, Museums and Material Culture. New York, USA: Berg.

Evans, G. W. (1995). Learning and the Physical Environment. In J. H. Falk \& L. D. Dierking (Eds.), Public Institutions for Personal Learning (pp.119-126). Washington DC: American Association of Museums.

Falk, J. H., \& Dierking, L. D. (1992) The Museum Experience. Washington, USA: Whalesback Books.

Falk, J. H., \& Dierking, L. D. (Eds.). (1995). Public Institutions for Personal Learning. Washington DC, USA: American Association of Museums.

Falk, J. H., \& Dierking, L. D. (2002). Lessons without Limit. How free-choice learning is transforming education. Plymouth, UK: Altamira.

Gardner, H. (2011). Frames of Mind. The Theory of Multiple Intelligences. New York, USA: Basic Books.

Golding, V. (2009). Learning at the museum frontiers. Identity, Race and Power. Surrey, UK: Ashgate.

Hale, J. (2012). Narrative environments and the paradigm of embodiment. In Macleod, S., Hanks, L.H. \& Hale, J. (Eds.) Museum Making. Narratives, architectures, exhibitions. (pp.192-200). Abingdon, UK: Routledge.

Hedge, A. (1995) Human-Factor Considerations in the Design of Museums to Optimize their Impact on Learning. In Falk, J.H. \& Dierking, L.D., (Eds.). (1995). Public Institutions for Personal Learning (pp.105118). Washington DC, USA: American Association of Museums.

Hein, G.E. (1998). Learning in the Museum. Abingdon, UK: Routledge.

Henning, M. (2006). Museums, Media and Cultural Theory. Maidenhead, UK: Open University Press.

Hood, M.G. (1993). Comfort and Caring. Two Essential Environmental Factors. Environment and Behavior, Vol.25, n.6, 710-724.

Hooper-Greenhill, E. (Ed.). (1994). The Educational Role of the Museum. Abingdon, UK: Routledge.

Howes, D. (Ed.). (2004). Empire of the Senses. The sensual cultural reader. New York, USA: Berg.

Hubard, O.M. (2007). Complete Engagement: Embodied Response in Art Museum Education. Art Education, Vol. 60, n.6, 46-53.

Kaplan, S. (1993). The Museum as a restorative environment, Environment and Behavior, Vol.25, n.6, 725-742.

Kolb, D.A. (1984). Experiential learning: experience as a source of learning and development. New Jersey,USA : Prentice-Hall.

Lave, J. \& Wenger, E. (1998). Communities of Practice: Learning, Meaning, and Identity. Cambridge, UK: Cambridge University Press. 
Maslow, A. (1970). Motivation and personality. New York, USA: Harper \& Row.

Mostafavi, M., \& Zumthor, P., (Eds.) (1996) Thermal Baths at Vals. London: Architectural Association.

O'Doherty, B. (1999). Inside the White Cube: the ideology of the gallery space. Berkeley, USA: University of California Press.

Pallasmaa, J. (2005). The eyes of the skin. West Sussex,UK: John Wiley \& sons.

Rosa, P. (2011). Una mostra per "fare" comunità in 'Fare gli Italiani' 18612011. Milan: SilvanaEditoriale.

Skolnick, L. H. (2005). Towards a new museum architecture. Narrative and representation. In S. Macleod (Ed.) Reshaping Museum Space. Architecture, design, exhibitions (pp. 118-130). Abingdon, UK: Routledge.

Sommers, R. (1969). Personal space. The behavioral basis of design. New Jersey, UK: Prentice Hall.

Toon, R. (2005) Black box science in black box science centres. In Macleod, S. (Ed.) Reshaping Museum Space. Architecture, design, exhibitions. (pp.26-38). Abingdon, UK: Routledge.

Weil, S. (2002). Making Museums Matter. Washington, USA: Smithsonian Institution.

Witcomb, A. (2003). Re-imagining the museum: beyond the mausoleum. Abingdon, UK: Routledge.

\section{Abstract}

The present paper is an enquiry on the contribution of bodily and sensory forms of engagement in the museum experience. While the latter has been often researched from cognitive and social perspectives, the more recent surge in interactive displays, immersive environments and dynamic architectural forms has triggered attention and need for a greater understanding of the physical, multisensory dimension of the museum visit. This can be explored in terms of hands-on displays and engagement with objects, but also as a multifaceted enveloping experience, involving the range of physical elements of the visit within a wide multisensory complex. From this perspective, the museum is understood as a three-dimensional narrative environment, a medium in itself, that makes use of an interconnected set of media, but whose specificity is given by its sensory and spatial dimension. In Part I, the role of this body-space component is framed within communication and learning theories and is explored through a review of publications in multiple fields. In Part II, the topic is subject of a direct field enquiry. One case-study of the original research is chosen for the purpose of this paper.

Key words: Body, senses, narrative, space

\section{Résumé}

Cette présentation rend compte d'une recherche sur la contribution corporelle et les formes sensorielles d'engagement au sein de l'expérience muséale. Si cette dernière a été plutôt observée du point de vue social et cognitif, les pratiques contemporaines utilisant des présentations interactives, des environnements immersifs, aussi bien que des espaces architecturaux dynamiques, nous incitent à une meilleure compréhension de la dimension physique et multisensorielle de la visite muséale. Celle-ci peut être considérée pas seulement en terme, par exemple, d'écrans tactiles, mais au contraire comme une expérience ample, complexe et enveloppante, qui implique une variété d'interactions physiques et perceptives. Dans la première partie, la dimension corporelle-spatiale est confrontée avec les théories de la communication et de l'apprentissage, et retracée dans des publications multidisciplinaires. Dans la deuxième partie, le thème est exploré en prenant comme 
exemple un cas concret. Ce dernier a été choisi parmi les cas de la recherche originale spécialement pour cette présentation.

Mots clé : Corps, sens, narrative, espace 